\title{
Torus Mandibularis: Etiology and Bioarcheological Utility
}

\author{
Brenna Hassett \\ University College London Institute of Archaeology, London, United Kingdom
}

\begin{abstract}
Torus mandibularis is a non-metric trait commonly recorded in bioarcheological investigation and often included in the battery of non-metric traits used to analyse biological distance among populations. However, there is considerable debate regarding the etiology of the trait, with genetic and environmental factors both having been posited as the primary factor in torus development. This study of 498 individuals, drawn from eight archeological samples, investigates the variation in torus frequency in different groups as
\end{abstract}

Torus mandibularis is a non-metric trait found in varying frequencies among human populations past and present, and as such is commonly recorded along with a battery of other such traits during the archeological assessment of skeletal remains. Nonmetric traits are largely used in analyses of biological distance within and among archeological samples due to the assumption of a high heredity quotient in their occurrence. Berry and Berry (1967) established the utility of several skeletodental traits in biodistance analyses, but several traits commonly included in such analyses lack substantive evidence of genetic involvement.

Torus mandibularis was chosen to test the utility of the trait in establishing biological relationships specifically because of the debate surrounding its etiology. Lacking a clear pattern of genetic inheritance, the trait has been seen by a number of researchers to relate instead to the osteological response of the masticatory complex to mechanical stresses. There has been nearly 100 years of contention as to whether the trait might represent a phenomenon related either to genetic heritability on a population level or to functional stress. This study was intended to provide direct evidence of either a correlation between occurrence and functional stresses on the masticatory complex, or a conclusive lack of correlation. Additionally, the degree to which this data set corresponds to other researchers' assessments of population-level variation is addressed. A total of 498 individuals from 8 archeological collections was assessed here on factors that have been posited to play a role in

Editor's note: Ms. Hassett's paper was awarded First Prize for 2005 in the Albert A. Dahlberg student research competition sponsored by the Dental Anthropology Association. defined by sample, age, sex, and measures of functional stress. Frequencies varied significantly among both samples and dental attrition categories, supporting the idea that mandibular tori are a threshold trait, influenced by both genetic and environmental factors. Results of this study suggest the utility of mandibular tori in bioarchaeology may lie outside of biodistance analyses that rely on the high heritability quotient of non-metric traits to establish population distances. Dental Anthropology 2006;19:1-14.

torus development, namely population group, age, sex, and evidence of functional stress.

Torus mandibularis is recognized as a bony ridge or series of bony nodules or lumps appearing on the lingual surface of the alveolar margin of the mandible, generally in the premolar region (Hauser and DeStefano, 1989). These tori may be completely absent or present in varying degrees, and may present a variety of forms.

Mandibular tori are not associated with any pathological condition and can be easily distinguished from instances where osteological activity is the result of a pathological condition causing abnormal growth, such as trauma or tumor. Torus mandibularis is generally manifested bilaterally, though it may be present just on one side of the mandible. There is often a degree of asymmetry between sides, with the right side most commonly presenting a more pronounced torus than the left (Haugen, 1990; Seah, 1995).

\section{ETIOLOGICAL DEBATE}

The question of etiology is vital in assessing whether use of oral tori in biodistance analysis is appropriate. If tori are assumed to be solely under genetic control, then mandibular exostoses are accepted as useful estimators of population distance along with the other traits commonly used as part of the battery of non-metric traits established by Berry and Berry (1967). If, however, environmental factors play a larger role in determining trait frequency, then their use as estimators of population affinity is not acceptable. The relative importance of environmental compared to genetic factors in the

Correspondence to: Brenna Hassett, 5 Oakworth Court, 160 Nelson Road, London N8 9RP, UK

E-mail: brennaryan_1@hotmail.com 
development of facial tori has been widely debated, with arguments for the functional basis of tori being contradicted by arguments for a higher genetic factor in increasing tori incidence. The trend has been to observe an increasing role for genetic causality, but it remains to be seen whether genetic inheritance fully explains the development of mandibular exostoses. The most recent studies have suggested that the tori arise in response to both genetic and environmental factors (Haugen, 1990; Seah, 1995). There are several particular aspects of tori distribution that have served as foci for debate, and multiple hypotheses that have been constructed to address the significance of population, sex, age, evidence of functional stress, robusticity of mandible, symmetry, and trait interaction in the formation of the mandibular tori.

Multiple studies attempting to assess the heritability of torus mandibularis have been conducted, coming to divergent conclusions - autosomal recessive (Krahl, 1949; Alvessalo and Kari, 1972), autosomal dominant (Suzuki and Sakai, 1960), or polygenetic in origin (Johnson et al., 1965; Sellevold, 1980) - that there is a strong argument against a simplistic assumption of genetic transmission of the trait. However, it has been commonly found to occur in family groupings, and children whose parents exhibited the trait were found to be more likely to exhibit the trait themselves in a study of modern Thais (Kerdpon and Sirirungrojying, 1999).

The explanation for these diverse findings may lie in the work undertaken by researchers to establish the heritability of non-metric traits in studies of mice and non-human primates. Grüneberg (1963) established the concept of quasi-continuous variation in nonmetric traits, positing that the size or rate of formation of a given trait may be the inherited factor, which he demonstrated by using genetically isolated strains of mice. Wright (1968) followed this by suggesting the idea of a "threshold" trait that appears only once a certain point determined by environmental factors has been crossed; what the individual inherits is a liability towards developing a trait which environmental factors act upon. Berry and Berry (1967) undertook to study the genetic origins of a large battery of non-metric traits in mice, and it is to this work that most researchers utilizing non-metric traits in estimating biological distance refer. Observing the analogues of several human skeletal traits in generations of mice, they proposed that most of the human non-metric traits also originate from normal genetic variation. The degree to which the environment influences mandibular torus prevalence, and the degree to which genetic inheritance does, should be understood in order for this particular non-metric trait to be included in the battery of traits assembled by Berry and Berry (1967) commonly used to establish biological distance among populations.

Factors affecting this debate include the difference in age and sex. Variation between age classes in tori frequency and degree of expression has not been found by all researchers (Hauser and De Stefano, 1989:9), but the largest studies suggest that there is some degree of variation (Eggen, 1954; Korey, 1980; Haugen, 1990; Jainkittivong and Langlais, 2000; Ruprecht et al., 2000). Researchers have found in some cases that males are more likely to exhibit tori than females (Haugen, 1990; Seah, 1995; Hjertstedt et al. 2001), whilst in others there is no significant sex difference (e.g., Bernaba 1974), or that females have higher frequencies of tori (Corruccini, 1974). A brief summation of the disparate results of some of these studies may be found in Table 1. The consensus appears to suggest that there is some degree of sexual dimorphism (Trinkaus, 1978; Haugen, 1990; Seah, 1995), but it is difficult to assess whether this difference is significant in a statistical sense, particularly in archeological samples where sample sizes may be small.

Variation in tori prevalence and expression with increasing evidence of functional stress to the masticatory complex has been the cornerstone of arguments for the primacy of environmental factors in the development of oral tori. Proponents of this view suggest that differences among groups may be accounted for either entirely or partially by non-hereditary factors, in which case mandibular tori are unsuitable for assessing biological distance without consideration of complicating environmental factors. Instead, they would be of greatest utility in assessing differences in environmental factors such as diet or parafunctional use of the jaws. Patterns of dental attrition, as a result of masticatory hyperfunction related to diet or conditions such as bruxism, have been seen to co-occur with mandibular tori in a statistically significant way in several instances. This has not been a universal observation (e.g., Scott et al., 1991). Sirirungrojying and Kerdpon (1999) found that torus mandibularis was significantly $(\mathrm{P}<$ $0.005)$ more common in dental patients suffering from temporomandibular disorder (TMD), perhaps due to high levels of parafunctional activity, such as clenching and grinding of the teeth (bruxism). This led them to suggest that torus mandibularis could be viewed as an early indication of risk for TMD. Larsen (1997) also comments that the general robusticity of the masticatory complex may be closely correlated with the amount of stress placed on the jaws; for example, a smaller, more gracile jaw would be correlated with a softer diet.

Johnson (1959) studied the mechanical stress of the jaws in conjunction with bone histology. The conclusions of his research were published posthumously, however, and the specific details of his findings are not provided; there is just the supposition that tori may be interpreted from histologiy to be the result of functional stress (Johnson, 1959). No subsequent study has found any evidence to support this hypothesis (Haugen, 1990; Seah, 
TABLE 1. Frequencies of torus mandibularis in various groups, by sex

\begin{tabular}{lccl}
\hline \multicolumn{1}{c}{ Sample } & Males $(\%)$ & Females $(\%)$ & \multicolumn{1}{c}{ Citation } \\
\hline Poundbury & 16.3 & 10.9 & Farwell and Molleson 1993 \\
Cannington & 11 & 15 & Brothwell et al. 2000 \\
Ukranian & 0.0 & 1.5 & Cesnys and Kundruktova 1982a \\
Lapps & 26.8 & 38.8 & Schreiner 1935 $^{\mathrm{a}}$ \\
North American Whites & 6.5 & 8.1 & Corruccini 1974 \\
Eskimo & 58.1 & 35.2 & Dodo and Ishida 1987a \\
Canadian Eskimo & 85.3 & 80.0 & Dodo and Ishida 1987a \\
Aleuts & 71.7 & 75.9 & Dodo and Ishida 1987a \\
Brazilian Indians & 0.5 & 0.5 & Bernaba 1977 \\
Blacks & 6.1 & 6.2 & Corruccini 1974 \\
Japanese & 26.7 & 33.3 & Mouri 1976 \\
Ainu & 44.3 & 21.1 & Dodo and Ishida 1987a \\
Iglooik Eskimo & 38.7 & 40.8 & Mayhall and Mayhall 1971 \\
Hall Beach Eskimo & 41.5 & 32.1 & Mayhall and Mayhall 1971 \\
Norwegian & 6.36 & 8.53 & Haugen 1990 \\
\hline
\end{tabular}

${ }^{a}$ Cited in Hauser and DeStefano (1996).

1995). An earlier study by Van den Broek (1943), who had formerly supported the hypotheses of functional stress acting to produce the tori, investigated tori histology and found that the structure of the tori did not represent an obvious bony response to mechanical stress.

The symmetry of mandibular torus formation has also been called on to account for trait etiology. Ossenberg (1981) ascribes overall tori frequency to environmental factors, but maintains that the degree of expression and any resulting asymmetricality is a function of genetics. Korey (1980) suggests that genetic factors would be more likely to act equally on both sides of the mandible. McGrath et al. further emphasize the importance of assessing asymmetry in measuring non-metric traits, suggesting that asymmetrical development, insofar as it is correlated to environmental causes, may be a clue to an individual's ability to buffer stress (McGrath et al., 1984, p 401).

Another suggested explanation of the development of the tori is local inflammation of the periosteum, leading to torus formation (Schreiner, 1935). This was followed by Van den Broek after his (1943) investigation of torus histology failed to support the hypothesis that the tori are laid down to strengthen the structural integrity of the jaw. Little evidence has thus far been provided to further this hypothesis.

\section{HYPOTHESES TESTED}

Having examined previous approaches to understanding the etiology of torus mandibularis, several questions remain. Of primary interest here is the suitability of this non-metric trait for use in biodistance analyses; that is, whether there is sufficient genetic control of the tori to warrant its use as a marker of family or population group membership. The prevailing opinion in the most recent summaries of the issue is that mandibular tori are a quasi-continuous or threshold trait (Haugen, 1990; Seah, 1995), having both a genetic and environmental component. If this is accurate, then questions arise concerning what degree of influence

TABLE 2. Characteristics of the samples used in the study.

\begin{tabular}{|c|c|c|c|c|c|c|}
\hline Sample & $\mathrm{n}$ & Males & Females & Unknown & Location & Period \\
\hline Chumash & 47 & 19 & 23 & 6 & $\begin{array}{l}\text { California Coast, } \\
\text { Channel Islands }\end{array}$ & Prehistoric \\
\hline Abingdon & 103 & 39 & 43 & 21 & Oxfordshire, UK & Medieval \\
\hline Cannington & 101 & 47 & 37 & 3 & Somerset, UK & $\begin{array}{l}\text { Dark Ages and } \\
\text { Late Roman (7-8th c. AD) }\end{array}$ \\
\hline Spitalfields & 100 & 48 & 31 & 12 & London, UK & 17th-19th century \\
\hline Poundbury & 71 & 29 & 32 & 9 & Dorchester, Dorset, UK & Roman 4th c. AD \\
\hline Hawara & 50 & 28 & 17 & 5 & Hawara, Fayum, Egypt & Roman 2nd-3rd c. AD \\
\hline Egypt & 23 & 10 & 9 & 4 & Abydos, Egypt & Pre- to Dynastic Period \\
\hline Lachish & 13 & 4 & 8 & 1 & Lachish, Israel & Mixed Bronze, Iron Age \\
\hline
\end{tabular}


each factor has on trait prevalence. To address these questions and the impact of the major factors on torus development posited by previous research, the following hypotheses have been formulated.

Firstly, if there is a genetic component to trait prevalence, different ethnic or population groups should show different frequencies of trait development. This does not, of course, rule out any environmental influence, but merely establishes the possibility that genetics could play a role. To firmly establish the genetic etiology of the tori would require a carefully controlled study covering generations, which was not feasible here.

Secondly, significant variation between the sexes would show that there is a level of sexual dimorphism to tori development. If the rates of sexual dimorphism differ significantly from sample to sample, this would indicate that the major force acting on dimorphism for these traits is environmental, rather than genetic, as the mode of genetic transmission of the trait is assumed to not vary between populations, while culturally differentiated sexual labor roles may differ.

Thirdly, variation between age groups in tori prevalence would reflect a difference in frequency caused by either progressive development of the exostoses or by a dynamic process related to functional stress. If the occlusal attrition and robusticity of the mandible are strongly correlated with age and tori prevalence, then the latter hypotheses may be supported. If there is little correlation between indicators of masticatory stress, age, and prevalence, then progressive development would be supported by significant variation between age classes.

Finally, the indications of masticatory hyperfunction-particularly tooth wear-would be greater in individuals with mandibular tori if masticatory hyperfunction is a large factor in determining tori prevalence.

\section{MATERIALS AND METHODS}

The materials used in this study come from the large collection of human skeletal material held by the Department of Anthropology of the Natural History Museum of London. The collection comprises material from over 20,000 individuals, gathered throughout the 19th, 20th, and 21st centuries from archeological excavations, anthropological fieldwork, and donated private collections (R. Kruzynski, pers. comm.). The larger coherent samples included here were largely archeological samples, groups that were spatially and chronologically limited to the time and location of excavated burials. The ideal sample size, based on both statistical and temporal concerns, was established as 100 individuals for each population. However, this was not possible in all cases. Some samples were comprised of fewer than 100 individuals, such as the Egypt group, which remains in the final analysis despite the smaller size in an effort to broaden the regional scope of the study. The Lachish sample was dramatically limited by the disassociation of mandibles from crania and was not considered sufficient to be included as anything other than an ancillary note in the population-based analysis, though it is included in the overall analyses. A summary of the samples included here is given Table 2 .

On the individual level, inclusion was dictated by several criteria. As mentioned above, and particularly in the case of the Lachish sample, all groups were of course limited by the number of individuals with associated mandibles. Additionally, inclusion occasionally depended on the level of preservation encountered, as the most fragmented remains could not be scored for all points of interest. In order to avoid biasing the samples in favor of more robust crania less likely to suffer a high degree of fragmentation, however, every effort was made to include both fragmented and non-fragmented remains where scores could be taken. Exclusion of individuals only occurred where it was not possible to take the scores of presence or absence of the tori.

For the collected data, a total of 41 measurements or scores were taken and used to create the final scores that are used in analysis. The aim behind the selection of these measurements was to provide standardized and, thus, easily comparable, data on age, sex, trait expression and frequency, mandibular thickness, temporomandibular joint remodeling, and tooth macrowear. Where published figures on the samples investigated here were available, they were compared with the assessments of this study. Age and sex assignments were established solely on cranial material due to the time constraints on the present study. Assignments were analyzed against previous published results drawn from both cranial and postcranial material, and in the exceptional case of the Spitalfields material, drawn from individuals of known age and sex. Insufficient discrepancy was found to warrant any adjustment of my own assessments, and because a standardized method was applied to all samples under discussion, the study is certainly internally coherent.

Age and sex were established after the Chicago Standards (Buikstra and Ubelaker, 1990). Not used here as a criteria for age estimation was the degree of dental attrition. Attrition, or the wear on the occlusal (chewing) surface of teeth, progresses with age, though at variable rates and is commonly used to assess biological age among archeological samples (Brothwell, 1986; Hillson, 1996). Samples may differ widely in their rates of attrition, as the amount of abrasive material in the diet and functional stress acting to wear the teeth differ among groups and even between the sexes (Walker et al., 1997, p 174). Lacking a comparable population with known age, sex, diet, and functional stresses, age estimates based on tooth attrition may be seriously distorted by a number of variables depending on the population in question. As attrition is also used here to examine the 


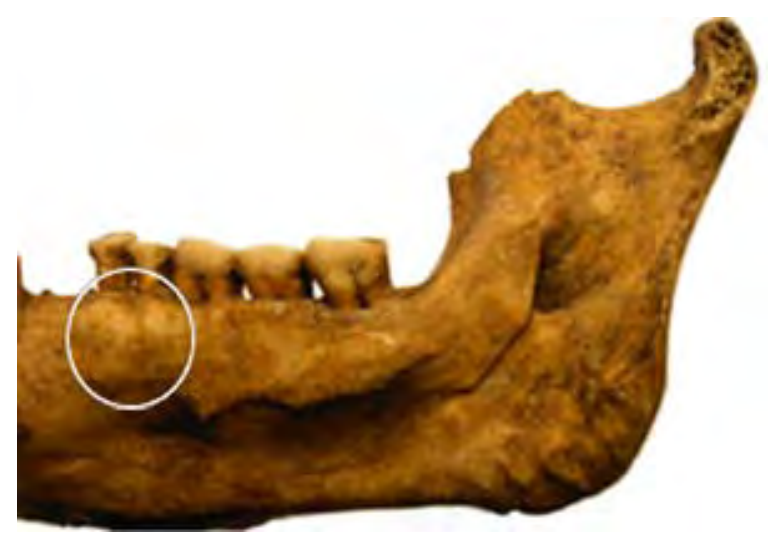

Fig. 1. Example of slight expression of torus mandibularis in a skull (SK34) from Cannington Cemetery (courtesy Natural History Museum, London).

functional stresses placed on the masticatory complex, the age estimates garnered from scoring tooth wear were excluded. Sutural closing of the cranium was used instead, though this method is rightfully criticized for its unreliability (Masset, 1976). Therefore, the age categories used here are very broad - young adult (17-34 years of age), adult (35-54 yr), and older adult (55+). This study counts trait presence in three categories, namely absent, unilateral, and bilateral. Metric equivalents of these categories (measured as maximum tori breadth on the transverse plane) are delineated in $2 \mathrm{~mm}$ increments with less than $2 \mathrm{~mm}$ being "slight," 2-4 mm "moderate," and greater than $4 \mathrm{~mm}$ "pronounced." Examples of the slight and moderate categories are provided in Figures 1 and 2. An example of the trait as it appears in a living individual can be found in Figure 3.

Attrition was scored at the left first and second molars, both upper and lower, and the "edentulous" category represents individuals who had premortem loss of the teeth. Remodeling activity at the temporomandibular joint (TMJ) was assessed on morphological changes to the joint surface both on the mandibular and the temporal

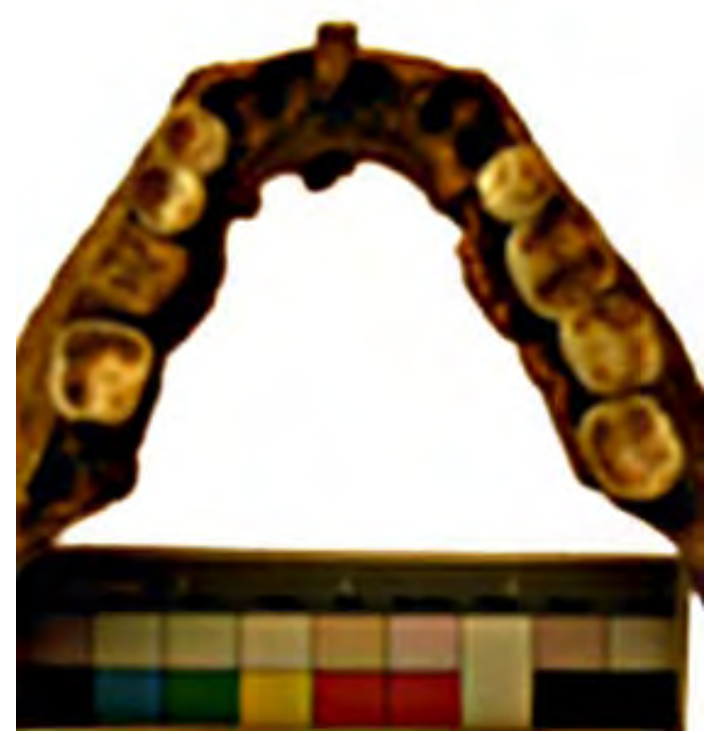

Fig. 2. Example of moderate expression of torus mandibularis in a skull (SK112) from Cannington Cemetery (courtesy Natural History Museum, London).

bones (e.g., excessive porosity, osteophyte activity).

Robusticity was of the mandible was assessed as the variable BODTH after Humphrey et al. (1999). The measurement is of mandibular body thickness, taken from the left side of the mandible by spreading calipers placed parallel to the occlusal plane at M1 in the center of the mandibular body. This measurement was seen to correlate strongly with overall metric measures of size in the mandible (Humphrey et al., 1999).

The presence of maxillary tori-a similar non-metric trait that is nearly identical to torus mandibularis in manner of expression and the degree of understanding regarding its etiology - was also recorded according to the same methodology as mandibular tori. As a second example of exostoses of the dental arch, this trait was considered likely to have similar factors affecting its

TABLE 3. Counts of unilateral and bilateral forms of torus mandibularis by sample ${ }^{1}$

\begin{tabular}{lcccc}
\hline Sample & Absent & Unilateral & Bilateral & Total \\
\hline Chumash & 47 & & 1 & 48 \\
Lachish & 13 & & & 13 \\
Hawara & 43 & 1 & 6 & 50 \\
Cannington & 65 & 2 & 24 & 91 \\
Abingdon & 98 & 2 & 3 & 103 \\
Spitalfields & 96 & 5 & 2 & 100 \\
Poundbury & 56 & 1 & 9 & 70 \\
Egypt & 20 & 13 & 2 & 23 \\
Total & 438 & 13 & 498 \\
\hline
\end{tabular}

${ }^{1}$ Chi-square $=56.639 ; \mathrm{df}=14 ; \mathrm{P}$ value $<0.000 ;$ chi square for unilateral and bilateral categories grouped as "present" $=41.348 ; \mathrm{df}=7 ; \mathrm{P}$ value $<0.000$. 


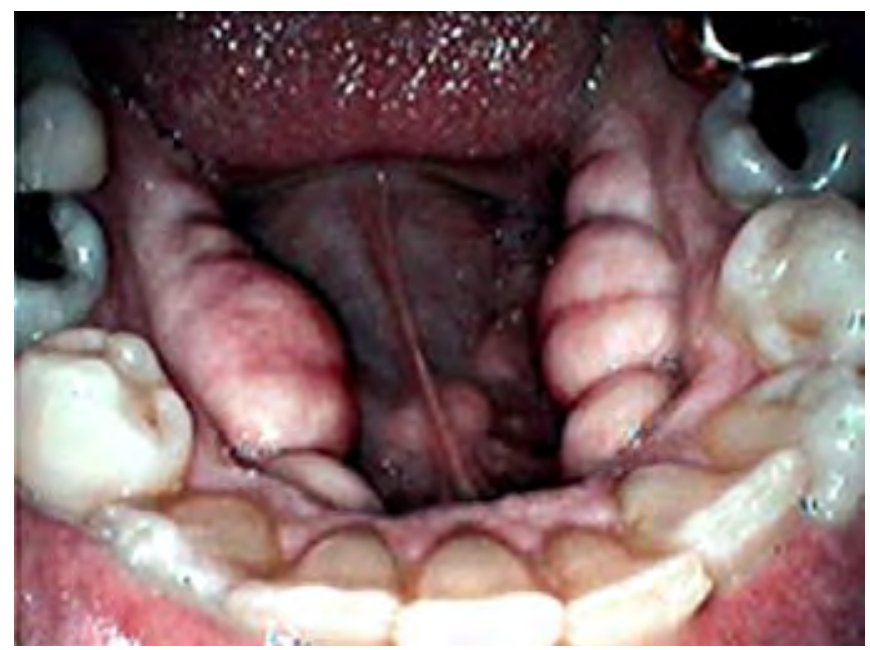

Fig. 3. Example of torus mandibularis in a living individual (courtesy S. Gill, Laguna Hills, CA).

development.

There were two primary areas in which the functional stresses placed on the masticatory complex were assessed in this study. The best skeletal evidence of stresses associated with excessive chewing and/or grinding motions necessitated by either a tough diet or a pathological condition (i.e., bruxism) in an individual is found in morphological changes in the masticatory apparatus (Eggen and Natvig, 1986). Representing these changes in the skeleton are, firstly, the degree of occlusal wear of the molar dentition of the upper and lower jaws, and, secondly, osteological activity in the TMJ.

\section{ANALYSIS}

All of the data collected for this study were entered into a computerized database to facilitate statistical and comparative analysis. This database was created in SPSS Version 11.0, a statistical processing application authored by Norusis (1994), which was used to produce the final analyses. The variables of interest were cross-tabulated in SPSS to provide the tables for this article. Chi-square tests were conducted for each cross-tabulation by SPSS, as well as correlation statistics. Generally, an alpha level of 0.05 was used to distinguish significant results, though trends that were discernable by direct observation of visual representations of data but fell slightly outside of the significant range are noted on occasion. Due to the small sample size provided by some of the groups, it is possible that some trends would be found to be significant if larger samples were available.

\section{RESULTS}

The tables included here give the results of the statistical cross-tabulation of the factors discussed above in tori frequency. All P-values given in the text are the result of Pearson's chi-square test unless otherwise noted. As with all archeologically derived data sets, it is important to remember that the standard statistical procedures used to test significance and correlations of variables assume a random sample of a normally distributed population, which is very rarely the case with archeological material. Therefore, where trends were observed in the distribution of the data but not deemed to be significant at the $\mathrm{P}<0.05$ level, they are

TABLE 4. Occurrences of torus mandibularis by age group and by sample.

\begin{tabular}{|c|c|c|c|c|c|c|c|c|c|c|c|c|}
\hline \multirow[b]{3}{*}{ Sample } & \multicolumn{12}{|c|}{ Age Group } \\
\hline & \multicolumn{4}{|c|}{ Less than $35^{2}$} & \multicolumn{4}{|c|}{ 35-54 Years $^{3}$} & \multicolumn{4}{|c|}{55 and Over ${ }^{4}$} \\
\hline & A & $\mathrm{U}$ & B & $\mathrm{T}$ & A & $\mathrm{U}$ & B & $\mathrm{T}$ & A & $\mathrm{U}$ & B & $\mathrm{T}$ \\
\hline Chumash & 11 & & 1 & 12 & 13 & & & 13 & 23 & & & 23 \\
\hline Lachish & 6 & & & 6 & 4 & & & 4 & 3 & & & 3 \\
\hline Hawara & 18 & & 1 & 19 & 15 & & 3 & 18 & 10 & 1 & 2 & 13 \\
\hline Cannington & 34 & & 11 & 45 & 12 & 1 & 6 & 19 & 19 & 1 & 7 & 27 \\
\hline Abingdon & 43 & & & 43 & 34 & 2 & 2 & 38 & 21 & & 1 & 22 \\
\hline Spitalfields & 17 & 1 & 1 & 19 & 41 & & 1 & 42 & 29 & 1 & 30 & 30 \\
\hline Poundbury & 7 & & 1 & 8 & 24 & 1 & 3 & 28 & 25 & 4 & 5 & 34 \\
\hline Egypt & 8 & & 1 & 9 & 9 & & & 9 & 3 & 1 & 1 & 5 \\
\hline Total & 144 & 1 & 16 & 161 & 152 & 4 & 15 & 171 & 133 & 8 & 16 & 157 \\
\hline
\end{tabular}

${ }^{1}$ Trait expression codes: Absent (A), Unilateral (U), Bilateral (B), and Total (T).

${ }^{2}$ Pearson chi square $=24.455 ; \mathrm{df} 14 ; \mathrm{P}$ value $=0.040 ;$ combining categories of presence $\mathrm{X}^{2}=15.634 ; \mathrm{df}=7 ; \mathrm{P}$ value $=$ 0.029 .

${ }^{3}$ Chi-square $=23.945 ; \mathrm{df} 14 ; \mathrm{P}$ value $=0.047 ;$ combining categories of presence $\mathrm{X}^{2}=16.788 ; \mathrm{df}=7 ; \mathrm{P}$ value $=0.019$.

${ }^{4}$ Chi-square $=25.636 ; \mathrm{df} 14 ; \mathrm{P}$ value $=0.029 ;$ combining categories of presence $\mathrm{X}^{2}=19.805 ; \mathrm{df}=7 ; \mathrm{P}$ value $=0.006$. 
TABLE 5. Occurrences of torus mandibularis by sex and sample

\begin{tabular}{|c|c|c|c|c|c|c|c|c|c|c|c|c|}
\hline \multirow[b]{2}{*}{ Sample } & \multicolumn{4}{|c|}{ Unknown $^{2}$} & \multicolumn{4}{|c|}{ Females $^{3}$} & \multicolumn{4}{|c|}{ Males $^{4}$} \\
\hline & A & $\mathrm{U}$ & B & $\mathrm{T}$ & A & U & B & $\mathrm{T}$ & A & $\mathrm{U}$ & B & $\mathrm{T}$ \\
\hline Chumash & 6 & & & 6 & 22 & & 1 & 23 & 19 & & & 19 \\
\hline Lachish & 1 & & & 1 & 8 & & & 8 & 4 & & & 4 \\
\hline Hawara & 5 & & & 5 & 14 & & 3 & 17 & 24 & 1 & 3 & 28 \\
\hline Cannington & 3 & & 3 & 6 & 27 & 2 & 8 & 37 & 35 & & 12 & 47 \\
\hline Abingdon & 20 & 1 & & 21 & 38 & 1 & & 39 & 40 & & 3 & 43 \\
\hline Spitalfields & 12 & & & 12 & 29 & 1 & 1 & 31 & 46 & 1 & 1 & 48 \\
\hline Poundbury & 7 & & 2 & 9 & 26 & 3 & 3 & 32 & 23 & 2 & 4 & 29 \\
\hline Egypt & 4 & & & 4 & 6 & 1 & 2 & 9 & 10 & & & 10 \\
\hline Total & 58 & 1 & 5 & 64 & 170 & 8 & 18 & 196 & 201 & 4 & 23 & 228 \\
\hline
\end{tabular}

${ }^{1}$ Trait expression codes: Absent (A), Unilateral (U), Bilateral (B), and Total (T).

${ }^{2}$ Chi-square $=23.514 ; \mathrm{df}=14 ; \mathrm{P}$ value $=0.052 ;$ combining categories of presence $X^{2}=16.826 ; \mathrm{df}=7 ; \mathrm{P}$ value $=0.019$.

${ }^{3}$ Chi-square $=23.435 ; \mathrm{df}=14 ; \mathrm{P}$ value $=0.054 ;$ combining categories of presence $X^{2}=18.307 ; \mathrm{df}=7 ; \mathrm{P}$ value $=0.011$.

${ }^{4}$ Chi-square $=27.631 ; \mathrm{df}=14 ; \mathrm{P}$ value $=0.016 ;$ combining categories of presence $\mathrm{X}^{2}=18.888 ; \mathrm{df}=7 ; \mathrm{P}$ value $=0.009$.

still described, but all results should be viewed with this caveat in mind.

\section{Populations}

Highly significant variability in frequency of occurrence of torus mandibularis was found among the samples in this study $(\mathrm{P}<0.000)$. Table 3 provides the frequencies by sample of mandibular tori, along with the results of chi-square tests for significance. Variation in frequency of torus mandibularis among age groups defined by degree of sutural closing, as shown in Table 4 , was also found to be significant among samples. The variability in prevalences between the sexes in different samples is greater for males $(\mathrm{P}<0.09)$ than females $(\mathrm{P}$ $<0.11)$ or those of unknown sex $(\mathrm{P}<0.19)$, as shown in Table 5 .
Also found to be highly significant was the variability of mandibular torus expression (torus size) among groups $(\mathrm{P}<0.000)$, as seen in Table 6 .

\section{Sex}

The degree of expression of the torus (whether slight, moderate, or pronounced) did not vary significantly between sexes. As mentioned above, however, variability between the sexes is evident among samples, particularly in males.

\section{Age}

Variation among age groups for mandibular tori, as defined by sutural closing, was not significant unless, as with sex, "group" is added as a variable. However,

TABLE 6. Occurrence of torus mandibularis expression by sample ${ }^{1}$

\begin{tabular}{lccccc}
\hline & \multicolumn{2}{c}{ Torus Mandibularis Expression } & \\
Sample & Absent & Slight & Moderate & Pronounced & Total \\
\hline Chumash & 47 & 1 & & & 48 \\
Lachish & 13 & & & & 13 \\
Hawara & 42 & 7 & 8 & 1 & 49 \\
Cannington & 65 & 17 & 1 & & 91 \\
Abingdon & 98 & 5 & 4 & & 103 \\
Spitalfields & 96 & 3 & & & 69 \\
Poundbury & 55 & 10 & 13 & 1 & 23 \\
Egypt & 20 & 3 & 46 & & 496 \\
Total & 436 & 46 & & & \\
\hline
\end{tabular}

${ }^{1}$ Chi-square $=55.688 ; \mathrm{df} 21 ; \mathrm{P}$ value $=0.000 ;$ combining trait expressions, $\mathrm{X}^{2}=54,280 ; \mathrm{df}=14 ; \mathrm{P}$ value $=0.000$. 
TABLE 7. Occurrence of torus manibularis by grade of occlusal attrition on LM1 ${ }^{1}$

\begin{tabular}{crrrrrrrrrr}
\hline Torus & & \multicolumn{7}{c}{ Grade of LM1 Attrition $^{1}$} & \multicolumn{1}{c}{ Total } \\
\hline mandibularis & 1 & 2 & 3 & 4 & 5 & 6 & 7 & 8 & 9 & T \\
\hline Absent & 1 & 14 & 51 & 67 & 43 & 31 & 17 & 29 & 149 & 402 \\
Unilateral & & 1 & 2 & & 2 & 1 & & 2 & 3 & 11 \\
Bilateral & & 1 & 2 & 16 & 4 & 5 & 9 & 4 & 4 & 45 \\
Total & 1 & 16 & 55 & 83 & 49 & 37 & 26 & 35 & 156 & 458 \\
\hline
\end{tabular}

${ }^{1}$ Chi-square $=55.688 ; \mathrm{df}=21 ; \mathrm{P}$ value $<0.000 ;$ combining grades of presence $\mathrm{X}^{2}=27.430 ; \mathrm{df}=8 ; \mathrm{P}$ value $=0.001$.

if age were to be defined by dental attrition classes as opposed to sutural closing, very significant variation in torus mandibularis is observed. The results of such a comparison are given under the Functional Stress: Attrition heading below. Torus mandibularis expression was not seen to vary between age classes.

\section{Functional stress: attrition}

Torus mandibularis showed significant variation in frequency between classes of occlusal tooth wear in the lower first molar $(\mathrm{P}<0.001)$, as shown in Table 7. Significant $(\mathrm{P}<0.01)$ differences between degree of expression of the mandibular tori in the different attrition classes was observed and may be seen in Table 8 .

\section{Functional stress: mandibular robusticity}

No significant variation was found between size categories of mandible and occurrence of torus mandibularis as measured by maximum mandibular breadth and defined in millimetre increments. Nor was any significance seen in the variation in degree of torus expression between size categories.

\section{Functional stress: activity at TMJ}

There was no significant difference in levels of osteophyte activity or porosity at the temporomandibular joint and degree of torus mandibularis expression or the incidence of mandibular tori.

\section{Trait interaction}

No significance was attached to the co-occurrence of mandibular and maxillary tori or to the degree of expression of either tori with co-occurrence or the degree of expression of the co-occurring tori.

\section{DISCUSSION}

"Group" appears to be a significant variable in prevalence of torus mandibularis and torus maxillaris. The results of this study are not surprising in confirming what is already an observed trend in the literature on the subject; that tori incidence rates vary widely according to group. The trait is seen here to occur in different frequencies and to different degrees in geographically and chronologically separated groups. No previous investigations of tori incidence have contested this variability, yet there remains a multitude of hypotheses as to why this variation occurs. It is useful to look to the reasons why multiple studies have reached such divergent conclusions in the light of the results of the present study.

Perhaps the largest factor in the disparity of conclusions arises from the different variables assessed among investigations. The variables tested in other works may have been chosen based on assumptions on the investigators part as to what factors could be involved in tori development. Thus, in those studies that began with an assumption of genetic inheritance acting as the sole factor (Suzuki and Sakai, 1960; Gould, 1964),

TABLE 8. Grade of torus manibularis tabulated against grade of occlusal attrition on LM1 ${ }^{1}$

\begin{tabular}{|c|c|c|c|c|c|c|c|c|c|c|}
\hline \multirow{2}{*}{$\begin{array}{c}\text { Torus } \\
\text { mandibularis } \\
\end{array}$} & \multicolumn{9}{|c|}{ Grade of LM1 Attrition $^{1}$} & \multirow[b]{2}{*}{ Total } \\
\hline & 1 & 2 & 3 & 4 & 5 & 6 & 7 & 8 & 9 & \\
\hline Absent & 1 & 14 & 51 & 67 & 42 & 31 & 17 & 29 & 148 & 400 \\
\hline Slight & & 2 & 2 & 11 & 5 & 5 & 7 & 4 & 6 & 42 \\
\hline Moderate & & & 2 & 5 & 1 & 1 & 2 & 1 & 1 & 13 \\
\hline Pronounced & & & & & & & & 1 & & 1 \\
\hline Total & 1 & 16 & 55 & 83 & 48 & 37 & 26 & 35 & 155 & 456 \\
\hline
\end{tabular}

${ }^{1}$ Chi-square $=42.059 ; \mathrm{df}=24 ; \mathrm{P}$ value $=0.013$. 
TABLE 9. Grade of torus mandibularis partitioned by whether the cases was dentate or edenulous ${ }^{1}$

\begin{tabular}{lccc}
\hline $\begin{array}{c}\text { Torus } \\
\text { mandibularis }\end{array}$ & Dentate & Edentulous & Total \\
\hline Absent & 366 & 69 & 435 \\
Unilateral & 13 & & 13 \\
Bilateral & 45 & 2 & 47 \\
Total & 424 & 71 & 495 \\
\hline
\end{tabular}

${ }^{1}$ Chi-square $=6.887 ; \mathrm{df}=2 ; \mathrm{P}$ value $=0.032$.

it is unsurprising that family relationships were the only variables considered. Unfortunately, family relationships are very difficult to ascertain in archeological samples, and these could not be considered here. However, the disparity of modes of inheritance posited by familial studies and the concurrence of environmental factors with the frequency of tori suggest that a simple Mendelian-mode of inheritance is not adequate to explain the variation in tori incidence among samples. Other factors seem to play a role in determining the prevalence of these traits.

As significant differences were found between the sexes in only some of the samples, the conclusions of previous researchers of an actual difference in prevalence rates between males and females, regardless of group, appear unsupported. However, as sexual dimorphism is known to differ in degree among groups (Brothwell, 1981), it is possible that the variation observed here is a product of this difference, acting to influence robusticity of the masticatory complex. Additionally, culturally defined sexual roles may include different functional stresses for men and women, further skewing any evidence of an actual tendency in tori prevalence should functional stress be a factor in development of the trait. It is worth noting here that Haugen (1990) observed greater frequency of mandibular tori in Eskimo men, though the ethnographic accounts of Pederson (1944) make it clear that Eskimo women had greater functional stresses placed on their jaws.

As with variability between sexes, the variability among age groups in development of the tori of the jaws is less obvious from the results of this study than that among groups. "Age" as a variable becomes especially problematic when it is assessed on skeletal material for a number of reasons. Because archeological samples do not generally provide individuals of known ages, the categorization of individuals into age groups must be done on the basis of morphological changes in the skeleton that are normally associated with ageing. These techniques are only accurate to the degree that other factors influencing the morphology of the skeleton can be controlled for. Walker (1978) points out that attrition rates depend not only on the age of an individual but also on the abrasiveness of the diet. The possibility that tori develop in response to the changing functional pressures on the jaw and teeth, along with this caveat, is why dental wear is not used here as an indication of age. This leaves the closing of cranial and palatine sutures as a basis for ageing the material studied here. An additional issue in using age as a variable arises, however, with the realization that the morphological changes to the cranium associated with age may be part of other skeletal processes affecting an individual's pattern of sutural closing (e.g., trauma, etc.). An overall tendency towards early or late ossification due to genetic or nutritional factors, or several other conditions (e.g., general tendency to robusticity, etc.) that affect the skeleton may act to conflate or deflate evidence of a relationship between chronological age and the development of tori. In the first case, all care was taken to remove individuals with obvious disruptions to the normal pattern of sutural closing. The possibilities associated with the second case are discussed further below, while the remaining multitude of possible factors acting to influence skeletal morphology must remain as a caveat in assessing the import of age in development of torus mandibularis and torus maxillaris.

The results of this investigation do show a significant variation between the age groups in development of mandibular and maxillary tori when "group" is added as a variable. This possibly reflects population-level differences in the morphological characteristics on which age was assigned, but other investigations have suggested that age is indeed a factor in tori development. Mandibular torus is very rare in juveniles, excepting those samples that normally have a high frequency of the trait (Haugen, 1990). Development of tori is generally agreed to begin within the first 30 years of life, though may occasionally occur later (Seah, 1995). The contention that tori development is not a slow, progressive process but rather a dynamic one (Seah, 1995, contra Haugen 1990) is perhaps supported by the evidence of this study, as degree of expression was not found to vary significantly among age classes. This has not been a universal finding; Halffman et al. (1992) and Eggen and Natvig (1986) found that tori were more frequent in the middle-aged, and Eggen (1989) also found no significant increase in frequency after $c a .30$ years of age. Johnson (1959), however, mentions that tori resorption, or shrinkage, has been observed in both the very old and those whose teeth have been removed. The results of this study show that the most significant variation in age groups between populations occurs within the 55+ age group $(P<0.03)$. These results suggest that is not so much a causal factor in development of the tori, but rather a covariant which is affected by the same factors acting to effect torus development.

The first and foremost of the variables associated with age is the degree of occlusal wear of the dentition. Tooth 
wear is strongly correlated with age, and commonly used in archeological samples to categorize age. In this study, tooth wear was significantly correlated with the age assignments $(r=0.233$, at a significance of $P<0.000)$. Generally, attrition increases with age (Walker, 1978; Brothwell, 1981; Waldron, 2001). But age is not the only factor acting to wear the dentition (Walker et al., 1991). Coarseness of diet or differing levels of functional stress on the teeth may hasten the normal process, with the result that individuals with different diets or stresses may show markedly different wear rates. Wear rates may be expected, then, to vary among groups (Walker, 1978). One of the most widely observed examples of this difference is found in the Eskimos of North America, Iceland, and Greenland, who have very high attrition rates as well as a high frequencies of chipping and pitting of the teeth that coincide with the high functional demands they place on them. In the samples observed here, there is a definite variability among rates of attrition, as evidenced by the molars.

The frequency of torus mandibularis is significantly correlated with the level of attrition recorded at the first molar $(P=0.000)$. The distribution of the tori over the wear classes clearly shows a gradual increase up to a peak in the number of occurrences around the fourth stage of wear, with the subsequent pattern of decline in frequency only occasionally interrupted. This is very suggestive when the reasons posited for development of the tori are considered. If the tori arise as a response to functional stress, evidenced by tooth wear, expectation is that the frequency of torus mandibularis would be low in individuals with low levels of wear. Frequency would be expected to increase as functional forces acting to wear the teeth increase. Should the tori develop as a skeletal response to mechanical forces, frequency would be expected to be highest in individuals with the most severe wear, with those exerting the most stress presumably exhibiting the most wear. However, frequency does not dramatically increase after the fourth stage of wear. A partial explanation for the lesser number of tori in the latter stages may be that, as tooth wear increases, the functionality of the teeth may be impaired, and the need for functional strengthening of the jaw may decrease if the jaw is no longer used due to tooth loss. The resorption of bone from the mandible in edentulous individuals due to this loss of function may partially explain the reduction of occurrence with the most severe wear. In examining torus mandibularis occurrences in dentulous and edentulous individuals, as defined by the premortem loss of the first and second molars, significant variability is found, which lends strength to this suggestion (Fig. 4).

This study did not find that osteophyte activity at the temporomandibular joint was significantly varied between those individuals with torus mandibularis. Nor was there a significant difference in levels of porosity.
This does not necessarily rule out the possibility of an association between disorders of the joint and the development of torus mandibularis; temporomandibular disorder (TMD) is only generally identifiable in the most severe cases from skeletal remains (S. Hillson, pers. comm.). In clinical studies, torus mandibularis has been seen to correspond very significantly $(P<0.0005)$ to TMD as well as to one of the most common causal factors for TMD, namely parafunctional activity such as bruxism (Kerdpon and Sirirungrojying, 1999).

Radiographic measures of bone density at multiple locations in the body taken in a study of torus mandibularis suggest that higher bone mass density is significantly associated with development of the trait (Hjertstedt et al., 2001), but, again, this was something the present study was unable to assess.

General robusticity of the jaw has been thought to have some relation to development of torus mandibularis. Eggen and Natvig (1986) suggested that individuals with better developed jaws had higher frequencies of torus mandibularis. Ossenberg (1981) hypothesized that the development of tori after puberty is possibly related to the greater food intake necessitated by growth, which in turn necessitates greater muscular power in order to process the larger amount of food. While many of the samples observed in the literature -with high prevalence rates of tori are generally robust in terms of skeletal build, the quality of robusticity is so ill-defined as to make analysis of this variable nearly impossible. With robusticity here defined by the thickness of the mandibular body, no significant

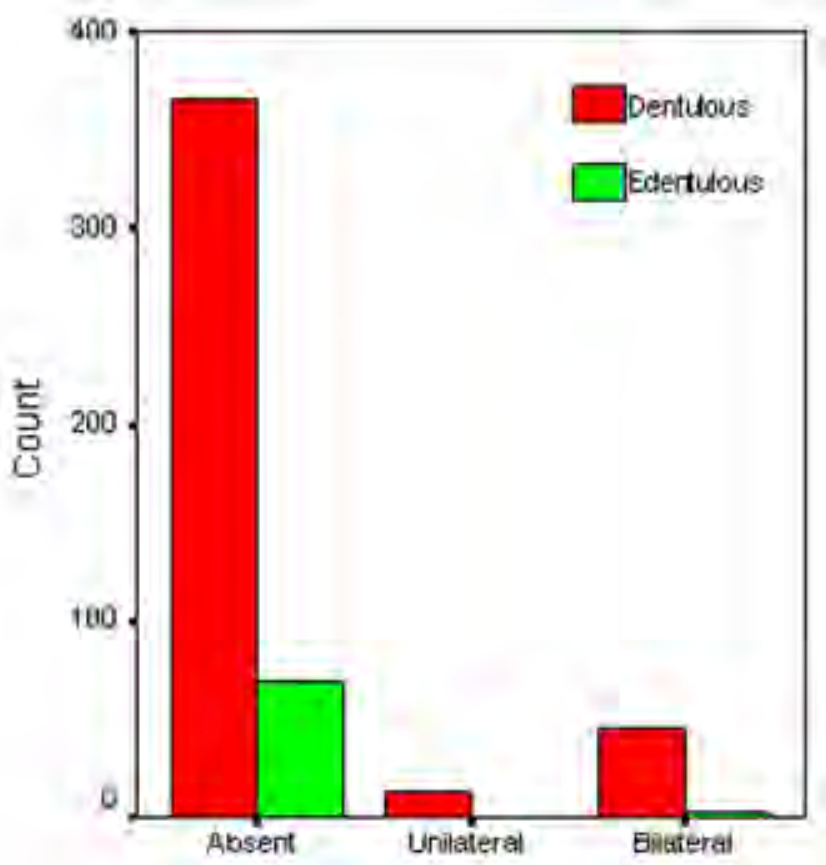

Fig. 4. Bar graph of the occurrence of torus mandibularis depending on whether the subject was dentate. 
relationship between torus mandibularis and general robusticity was observed.

This brings the discussion to the hypothesis of trait interaction. The concurrence of the two exostoses included in this study was insufficient to suggest a strong correlation. Other researchers have debated the co-occurrence of torus palatinus, with some finding a correlation between the traits and some not. The investigations using the largest sample sizes have not seen a strong correlation, and the investigations into the effects of bone mineral density (Hjertstedt et al. 2001) and parafunctional activities (Eggen, 1954; Eggen and Natvig, 1986; Kerdpon and Sirirungrojying, 1999) have shown different prevalence rates for torus palatinus. In this study, the co-occurrence of torus mandibularis and torus maxillaris was not found to be significant in either degree or expression of frequency of incidence. This finding, taken in conjunction with results showing no correlation between possible causal factors in torus mandibularis development and torus maxillaris development, suggests that the two traits are not the result of a single causal factor, either environmental or genetic. The lack of co-occurrence in familial studies of the traits and in studies of environmental or functional stress lead to the conclusion that the tori arise due to separate stimuli. That is not to say absolutely that the same factors aren't responsible for development of both maxillary and mandibular tori, but the inconclusive efforts to relate the maxillary tori to those factors, which show a significant relation to mandibular tori, suggest that the developmental process of the former is not identical to the latter. Due perhaps to the rarity of torus maxillaris, less can be said about the possible correlations of environmental or functional stress. This finding follows logically in steps of the growing consensus that the other major tori of the jaw, torus palatinus and torus mandibularis, are affected by different factors (Kolas et al., 1983; Haugen, 1990; Seah, 1995).

In relation to the hypotheses surrounding torus etiology outlined previously, this study has found the following:

- Frequency of both mandibular and maxillary tori varies between populations to a significant degree, suggesting that genetic inheritance could play a role in torus etiology.

- Sexual dimorphism in tori frequency is found to be significant within some populations, but not significantly varied in others, possibly as a result of the different effects of culturally defined labour roles on the sexes. Additionally, this may explain the disparate results of previous work in establishing whether the traits are more prevalent in males, females, or neither.

- Age is not found to be a significant factor in torus development when measured on criteria other than dental attrition, suggesting a more dynamic, possibly environmentally induced, pattern of growth. While robusticity of the mandible was not strongly correlated with age or tori frequency, age was strongly correlated with attrition classes. The interaction of age with tooth wear is well established, which may explain why previous research has suggested age as a factor in torus development.

- Masticatory hyperfunction, evidenced by tooth wear, is seen to be correlated with mandibular torus prevalence. However, frequency of the trait is greatest at a lower level of wear and there is a pronounced difference in trait distribution between dentulous and edentulous individuals. This may suggest that mandibular tori are a successful response to functional stress, as opposed to the result of loss of masticatory function with increasing dental attrition

\section{CONCLUSIONS}

The results of this study conform to a pattern suggested by the most recent research into tori etiology. In the last 15 years, the general consensus has been that mandibular tori at least arise from a combination of genetic and environmental factors. A more consistent observation of any correlations, might have been observed, should they exist, if all investigations included the multiplicity of variables proposed as affecting the occurrence of mandibular torus. However, because research designs have often been constructed in a dichotomizing either/or fashion to show the significance of one particular variable in the development of tori at the expense of any other factors, there has been a tendency to include only those factors the investigator wishes to demonstrate as being either positively or negatively correlated with tori incidence. This is unfortunate, because the widely divergent results produced by such studies only serve to cloud the issue further. By incorporating as many variables as possible into an investigation of tori development, the polarised results of earlier studies become understandable as partial glimpses of a multifactorial etiology only discernable when a wide ranging investigation is carried out.

The results obtained here suggest that functional stress plays a large role in the development of mandibular tori. The correlation of age to torus development remains unclear, though it is vital to remember that tooth wear is strongly correlated with age. Had the age assessments used here relied on attrition categories to define age, as is common with archeological samples, the variation between age categories and attrition categories would be identical. A possible result of this correlation is the overemphasis of the importance of age in tori development, as the passage of time allows increasing amounts of wear and stress to act on the jaw. Significant variation in tori development between classes of tooth wear were found that support the idea of the torus arising as a response to functional stress acting on the mandible in the form 
of increased functional demand on the masticatory complex. However, histological studies have not borne out the expectation that the bony structure of the tori themselves would reflect the direction of this mechanical force. This leads to the conclusion that the exostoses of the mandible are not purely a skeletal response to pressure, an argument that also finds support in this study's finding a lack of significant correlation between overall mandibular robusticity and trait incidence. Further refuting the idea of a single variable, functional stress, as the sole causal factor in tori development, are the familial studies carried out in living populations of known biological relations. Variation among populations of different origins in torus frequency must be accounted for, and the most appropriate explanation may be found in the concept of the threshold trait as proposed by Wright (1963). If the inherited factor of torus mandibularis is a liability for development, an individual tendency towards formation of either this particular exostosis or exostoses in general, then etiology must be multi-factorial, with environmental factors acting to determine whether or not the threshold for development is surpassed. This model explains both the variability in frequency among groups and among dental attrition classes found in this study.

It is hoped that future research into the development of mandibular tori will address the issues raised by this study. Paramount of these issues is the establishment of a standardised method of recording the presence of the tori, which may only be accomplished by assigning metric categories to what have been somewhat arbitrary size distinctions. Additionally, the correlation between relatively good periodontal conditions and torus development should be investigated in a broader, crosspopulation context. A final direction of considerable interest is towards a better understanding of trait interaction, particularly between all exostoses of the face and skeleton, such as palatine and maxillary tori.

In conclusion, it seems necessary to reconsider the suitability of torus mandibularis for analysis of biological distance between populations. Unless environmental factors can be completely controlled for, population frequencies may differ or converge without relation to the degree of genetic relation between groups. This study has shown the significance of dental attrition in variance of torus mandibularis frequency, suggesting that environmental factors should be carefully weighed when assessing the genetic component of tori etiology. While the entire battery of non-metric traits is beyond the scope of this study, the findings related here suggest that careful consideration of trait etiology is a necessary step in choosing variables for biodistance analyses. Not all non-metric traits can be considered a priori products of genetic variation, as the investigation of the etiology of torus mandibularis shows.

\section{ACKNOWLEDGEMENTS}

The author gratefully acknowledges all of the assistance generously given by Dr. Simon Hillson and Dr. Daniel Antoine and Dr. Robert Kruzynski of the Department of Anthropology at the Natural History Museum of London. Additional thanks are in order to Dr. Louise Humphreys and to the entire staff of the Department of Anthropology at the Natural History Museum.

\section{LITERATURE CITED}

Alvesalo L, Kari M. 1972. A dental field investigation in Hailuoto, V. Torus mandibularis: incidence and some viewpoints connected with it. Proc Finn Dent Soc 68:307-314.

Axelsson G, Hedegard B. 1981. Torus mandibularis among Icelanders. Am J Phys Anthropol 54:383-389.

Berbier M. 1997. The discovery of the mummy portraits. In: Walker S, editor. Ancient faces. London: British Museum Press, p 32-33.

Bernaba JM. 1977. Morphology and incidence of torus palatinus and mandibularis in Brazilian Indians. J Dent Res 56:499-501.

Berry AC. 1974. Non-metrical variation in Scandinavian crania. Am J Phys Anthropol 40:345-358.

Berry AC, Berry RJ. 1967. Epigenetic variation in the human cranium. J Anat 101:361-379.

Berry RJ. 1968. The biology on non-metric variation in mice and men. In: Brothwell DR, editor. The skeletal biology of earlier human populations. London: Pergamon Press, p 103-134.

Brothwell DR. 1981. Digging up bones, 3rd ed. London: British Museum.

Brothwell DR, Powers R, Hirst SM, Wright SM, Gauthier S. 2000. The human biology. In: Rahtz P, Hirst S, Wright SM, editors. Cannington Cemetery. London: Society for the Promotion of Roman Studies, p 131256.

Buikstra JE, Ubelaker DH, editors. 1994. Standards for data collection from human skeletal remains. Fayetteville: Arkansas Archaeological Survey Research Series.

Christensen A. 1998. Biological affinity in prehispanic Oaxaca. Unpublished Ph.D. dissertation, Department of Anthropology, Vanderbilt University.

Corruccini RS. 1974. An examination of the meaning of cranial discrete traits for human skeletal biological studies. Am J Phys Anthropol 40:425-445.

Eggen S. 1954. Torus mandibularis and periodontal disease. Odontologica Tidskr 62:431-442.

Eggen S. 1988. Torus mandibularis and muscular hyperactivity. N Tannlegeforen Tid 98:220-226.

Eggen S. 1989: Torus mandibularis: an estimation of the degree of genetic determination. Acta Odontol Scand 47:409-415. 
Eggen S, Natvig B. 1986. Relationship between torus mandibularis and number of present teeth. Scand J Dent Res 94:233-240.

Eggen S, Natvig B. 1991. Variation in torus mandibularis prevalence in Norway. Community Dent Oral Epidemiol 19:32

Farwell DE, Molleson TI. 1993. Excavations at Poundbury 1966-80. Vol. II: The cemeteries. Dorchester: Dorset Natural History and Archaeological Society

Gould AW. 1964. An investigation of the inheritance of torus palatinus and torus mandibularis. J Dent Res 43:159-167.

Gower JC, Digby PGN. 1984. Some recent advances in multivariate analysis applied to anthropometry. In: van Vark GN, Howells WW, editors. Multivariate statistical methods in physical anthropology. Lancaster: D. Reidel Publishing Company, p 21-36.

Grüneberg H. 1963. Pathology of development. New York: Wiley Company.

Halffman CM, Scott GR, Pederson PO. 1992. Palatine torus in the Greenlandic Norse. Am J Phys Anthropol 88:145-161

Haugen LK. 1990. The tori of the human jaw skeleton. Antropologiske skrifter nr. 4. Oslo: Anatomisk Institutt, Universitetet i Oslo.

Hauser G, De Stefano GF. 1989. Epigenetic variants of the human skull. Stuttgart: E. Schweizerbart'sche Verlagsbuchhandlung (Nägele u. Obermiller).

Hillson S. 1996. Dental anthropology. Cambridge: Cambridge University Press.

Hjertstedt J, Burns EA, Fleming R, Raff H, Rudman I, Duthie EH, Wilson CR. 2001. Mandibular and palatal tori, bone mineral density, and salivary cortisol in community-dwelling elderly men and women. J Gerontol A Biol Sci Med Sci 56:M731-M735.

Hooton EA. 1918. On certain Eskimoid characters in Icelandic skulls. Am J Phys Anthropol 1:53-76.

Hrdlička A. 1940. Mandibular and maxillary hyperostoses. Am J Phys Anthropol 27:1-55.

Humphrey LT, Dean MC, Stringer CB. 1999. Morphological variation in great ape and modern human mandibles. J Anat 195:491-513.

Hylander WL. 1977. The adaptive significance of Eskimo craniofacial morphology. In: Dahlberg AA, Graber TM, editors. Orofacial growth and development. Paris: Mouton.

Jainkittivong A, Langlais RP. 2000. Buccal and palatal exostoses: prevalence and concurrence with tori. Oral Surg Oral Med Oral Pathol Oral Radiol Endod 90:48-53.

Johnson CC, Gorlin RJ, Anderson VE. 1965. Torus mandibularis: a genetic study. Am J Hum Genet 17:433-442.

Johnson O. 1959. The tori and masticatory stress. J Prosthet Dent 9:975-977.

Kerdpon D, Sirirungrojying S. 1999. A clinical study of oral tori in southern Thailand: prevalence and the relation to para-functional activity. Eur J Oral Sci107:9-13.

Kolas S, Halpern V, Jefferies K, Huddlestone S, Robinson HBG. 1953. The occurrence of torus palatinus and torus mandibularis in 2,478 dental patients. Oral Surg Oral Med Oral Pathol 6:1134-1141.

Konigsberg LW. 1988. Migration models of prehistoric postmarital residence. Am J Phys Anthropol 77:471482.

Korey KA. 1980. The incidence of bilateral nonmetric skeletal traits: a reanalysis of sampling procedures. Am J Phys Anthropol 53:19-23.

Krahl VE. 1949. A familial study of the palatine and mandibular tori. Anat Rec103:477.

Krogman W, Iscan MY. 1986. The human skeleton in forensic medicine. Springfield: Charles C. Thomas Publishing.

Larsen CS.1997. Bioarchaeology. Cambridge: Cambridge University Press.

Masset C. 1971. Erreurs systématiques dans la determination de l'âge par les sutures craniennes. Buletin Mémorial de la Societe Anthropologique du Paris 12:85-105.

Mayhall JT, Dahlberg AA, Owen DG. 1970. Torus mandibularis in an Alaskan Eskimo population. Am J Phys Anthropol 33:57-60.

Mayhall JT, Mayhall MF. 1971. Torus mandibularis in two Northwest Territories Villages. Am J Phys Anthropol 34:143-148.

McGrath JW, Cheverud JM, Buikstra JE. 1984. Genetic correlations between sides and heritability of asymmetry for nonmetric traits in rhesus macaques on Cayo Santiago. Am J Phys Anthropol 64:401-411.

Meindl RS, Lovejoy CO. 1985. Ectocranial suture closure: a revised method for the determination of skeletal age at death based on the lateral-anterior sutures. Am J Phys Anthropol 68:57-66.

Molleson T, Cox M, Waldron AH, Whittaker DK. 1993. The Spitalfields Project. Vol. 2. York: Council for British Archaeology.

Molleson T, Jones K. 1991. Dental evidence for dietary change at Abu Hureyra. J Archaeol Sci 17:455-468.

Moorrees CFA, Osborne RH, Wilde E. 1952. Torus mandibularis: its occurance in Aleut children and its genetic determinants. Am J Phys Anthropol 10:319329.

Morris NT. 1981. The occurrence of mandibular torus. In: Hayes AC, editor. Contributions to Gran Quivira archaeology. Washington, DC: National Park Service, Publications in Archaeology 17:123-127.

Norusis MJ. 1994. SPSS professional statistics 6.1. Chicago: SPSS Inc.

Ohno N, Sakai T, Mizutani T. 1988. Prevalence of torus palatinus and torus mandibularis in five Asian populations. Aichi Gakuin Dent Sci 1:1-8. 
Ossenberg NS. 1978. Mandibular torus: a synthesis of new and previously reported data and a discussion of its causes. In: Cybulsky JS, editor. Contributions to physical anthropology. Ottowa: National Museum of Canada, p 1-52.

Ossenberg NS. 1981. An argument for the use of total side frequencies of bilateral nonmetric skeletal traits in population distance analysis: the regression of symmetry on incidence. Am J Phys Anthropol 54:471-479.

Pederson PO. 1944. Dental notes and a chapter on the dentition. In: Broste $\mathrm{K}$, Fischer-Moller K, editors. The Medieval Norsemen at Gardar: anthropological investigations. Meddelelser øm Grønland 89:1-62.

Pederson PO. 1947. Dental investigations of Greenland Eskimos. Proc R Soc Med 40:726-732.

Prowse TL, Lovell NC. 1996. Concordance of cranial and dental morphological traits and evidence for endogamy in Ancient Egypt. Am J Phys Anthropol 101:237-246.

Sawyer DR, Allison MJ, Elzay RP, Pezzia A. 1979. A study of tous palatinus and torus mandibularis in Pre-Columbian Peruvians. Am J Phys Anthropol 50:525-526.

Schreiner KE. 1935. Zur Osteologie der Lappen. Aschenhoug, Series B. XVII. Oslo: Bd Inst Sammelign Kulturforskn, p 161-177.

Scott GR, Halffman CM, Pedersen PO. 1991. Dental conditions of Medieval Norsemen in the North Atlantic. Acta Archaeologica 62:183-207.

Scott GR, Turner CG. 1997. The anthropology of modern human teeth: dental morphology and its variation in recent human populations. Cambridge: Cambridge University Press.

Seah YH. 1995. Torus palatinus and torus mandibularis: a review of the literature. Aust Dent J 40:318-321.

Sellevold BJ. 1980. Mandibular torus morphology. Am J Phys Anthropol 53:567-572.
Sirirungrojying S, Kerdpon D. 1999. Relationship between oral tori and temporomandibular disorders. Int Dent J 49:101-104.

Sjøvold T. 1973. The occurrence of minor non-metrical variants in the skeleton and their quantitative treatment for population comparisons. Homo 24:204233.

Sjøvold T.1984. Areport on the heritability of some cranial measurements and non-metric traits. In: van Vark GN, Howells WW, editors. Multivariate statistical methods in physical anthropology. Lancaster: D. Reidel Publishing Company, p 223-246.

Smith BH. 1991. Standards of human tooth formation and dental age assessment. In: Kelley MA, Larsen CS, editors. Advances in dental anthropology. New York: Wiley-Liss, p 143-168.

Suzuki M, Sakai T. 1960. A familial study of torus palatinus and torus mandibularis. Am J Phys Anthropol 18:263-272.

Townsley W. 1948. The influence of mechanical factors on the development and structure of bone. Am J Phys Anthropol 6:25-45.

Trinkaus E. 1978. Asymmetry of human skeletal nonmetric traits. Am J Phys Anthropol 49:315-318.

Van den Broek AJP. 1943. On exotoses in the human skull. Acta Neerland Morphol 5:95-118.

Waldron T. 2001. Shadows in the soil. Stroud: Tempus Publishing.

Walker PL. 1978. A quantitative analysis of dental attrition rates in the Santa Barbara Channel area. Am J Phys Anthropol 48:101-106.

Walker PL, Dean G, Shapiro P. 1991. Estimating age from tooth wear in archaeological populations. In: Kelley MA, Larsen CS, editors. Advances in dental anthropology. New York: Wiley-Liss, p 169-178.

Wright S. 1968. Evolution and the genetics of populations: genetic and biometric foundations. Vol. 1. Chicago: University of Chicago Press. 